\title{
Promosi Program Dakwah Radio Selebes Gorontalo
}

\author{
Taufik R. Talalu ${ }^{1 *}$ \\ ${ }^{1}$ Jurusan Komunikasi dan Penyiaran Islam, Fakultas Ushuluddin dan Dakwah, Institut Agama Islam Negeri Sultan Amai, \\ Gorontalo, Jl. Gelatik No. 1 Kota Gorontalo, Indonesia, 96135 \\ *Email Korespondensi: trtalalu@iaingorontalo.ac.id
}

Kata kunci: Program Dakwah Promosi Radio

Keyword: Da’wah Program Promotion Radio

\section{A B S T R A K}

Penelitian ini membahas tentang promosi program dakwah Radio Selebes Gorontalo. Ada anggapan bahwa promosi program dakwah tidak penting dilakukan jika media penyiaran radio sudah lama beroperasi dan penduduk di daerah jangkauan siaran mayoritas beragama Islam. Padahal, promosi program merupakan unsur penting yang berkontribusi terhadap kelangsungan operasional radio. Penelitian ini menggunakan metodologi kualitatif dengan model studi kasus. Data dalam penelitian ini dikumpukan dengan teknik wawancara dan studi dokumentasi. Data dianalisis melalui tahapan pengumpulan data, reduksi data, display data, dan penarikan kesimpulan. Hasil penelitian menunjukkan bahwa tiga program dakwah dipromosikan menggunakan empat metode yaitu media sendiri, iklan, promosi penjualan dan pemasaran interaktif. Sementara public relation dan direct marketing tidak digunakan secara khusus untuk promosi program dakwah. Terbatasnya variasi metode yang digunakan disebabkan oleh kekhawatiran Selebes mengenai dampak biaya yang timbul akibat kegiatan promosi.

\section{A B S T R A C T}

This study is aimed to discuss the promotion of da'wah program of Selebes Radio Gorontalo. There is an assumption that the promotion of da'wah program is not important if the radio has been working for a long time and the population in the coverage area of its radio is predominantly Muslim. In fact, promotion is an important element that contributes to the continuity of the radio operations. This research used a qualitative methodology with a case study model. The data in this study were collected using interview techniques and documentation studies. Data were analyzed through stages of data collection, data reduction, data display, and conclusions. The results showed that three da'wah programs were promoted using four methods namely self-media, advertising, sales promotion and interactive marketing. Public relations and direct marketing are not used specifically for the promotion of da'wah programs. The limited variety of methods used is due to the concern of Selebes regarding the cost impact arising from promotional activities.

\section{PENDAHULUAN}

Keberlanjutan operasional media penyiaran radio dipengaruhi oleh dua unsur penting yaitu pendengar dan pemasang iklan. Promosi penting dilakukan sebagai upaya mempertahankan dan menambah pendengar serta pemasang iklan (Morrisan, 2013). Namun kenyataanya, promosi program dakwah dipandang tidak penting oleh manajemen Radio Selebes. Mereka berpandangan bahwa program dakwah tetap didengarkan meski minim promosi, bahkan tanpa promosi. Keberhasilan Selebes bertahan dalam industri media penyiaran radio di
Gorontalo dan kondisi penduduk yang mayoritas beragama Islam menjadi alasannya. Data menunjukkan bahwa 96,87 persen penduduk Provinsi Gorontalo beragama Islam (Gorontalo.bps.go.id, 2018). Meskipun bukan radio dengan format khusus agama, Selebes tetap menghadirkan program-program dakwah sebagai wujud kontribusi terhadap pengembangan. Hal ini sejalan dengan pendapat Nasor (2017) bahwa radio telah memberikan kontribusi dan pengaruh besar terhadap perkembangan dakwah. Radio punya andil, fungsi, dan peran dalam kegiatan dakwah. 
Kewajiban berdakwah tersirat dalam alqur'an surat An-Nahl ayat 125. Dakwah merupakan usaha yang dilakukan secara sadar untuk mengajak manusia menuju jalan Allah demi mencapai kebahagiaan di dunia dan di akhirat. Melalui ayat ini Allah menyeru manusia untuk berdakwah dengan tetap mengutamakan cara-cara yang baik (Zain, Maimun, \& Fuadi, 2017).



"Serulah (manusia) kepada jalan Tuhan-mu dengan hikmah dan pelajaran yang baik dan bantahlah mereka dengan cara yang baik. Sesungguhnya Tuhanти Dia-lah yang lebih mengetahui tentang siapa yang tersesat dari jalan-Nya dan Dia-lah yang lebih mengetahui orang-orang yang mendapat petunjuk."

Menurut Tafsir Al-Muyassar Kementrian Agama Saudi Arabia, Allah memerintahkan nabi Muhammad untuk menyeru dengan cara yang bijaksana agar jin dan manusia menuju agama Islam sebagaimana yang telah Allah wahyukan kepadanya. Senantiasa mengutamakan cara yang lembut saat memberi mereka pelajaran bermanfaat, serta menggunakan cara yang baik dan dalil-dalil yang kuat saat mendebat mereka yang menyelisihinya. Sungguh Allah Maha Mengetahui hamba-Nya yang ingin menuju jalan yang benar (Tafsirweb, n.d.).

Kehadiran podcast, media sosial seperti Facebook dan Instagram tidak membuat radio kehilangan pendengarnya. Diane Kemp, Profesor pada bidang broadcasting di Birmingham City University memprediksi bahwa radio tidak akan mati karena kemunculan podcast (Tirto.id, 2019). Nielsen Radio Audience Measurement menemukan bahwa penetrasi radio dianggap masih cukup baik sebab berada di angka 38 persen pada tahun 2016. Selain itu, masih ada sekitar 20 juta penduduk Indonesia menghabiskan waktu rata-rata 139 menit per hari mendengarkan radio (Nielsen.com, 2016).

Pada tahun 2018 penduduk Indonesia yang berusia 5 tahun keatas yang mendengarkan siaran radio selama seminggu terakhir sebanyak 12,73 persen. Jumlah ini termasuk 16,44 persen penduduk Provinsi Gorontalo, 21,89 persen penduduk di wilayah perkotaan dan 12,58 persen di wilayah perdesaan (Bps.go.id, 2019).

Promosi dilakukan agar media penyiaran radio tetap terus ada. Rahayu \& Katili (2019) telah membuktikan bahwa promosi merupakan bagian dari strategi mempertahankan eksistensi program radio. Rusdi (2011) mengemukakan bahwa demi memenangkan persaingan dalam industri media penyiaran radio, strategi komunikasi pemasaran dibutuhkan. Menurut Prisgunanto (2006) istilah promosi dan komunikasi pemasaran merupakan istilah yang pengertiannya disamakan. Begitu pun dengan istilah promotional mix atau promotion mix dan marketing communication mix. Crosier menjelaskan bahwa disamaartikannya istilahistilah ini sebab ada konteks pengertian yang sama dalam memahami 4Ps (Product, Price, Place, Promotion) atau elemen-elemen marketing mix (Prisgunanto, 2006). 


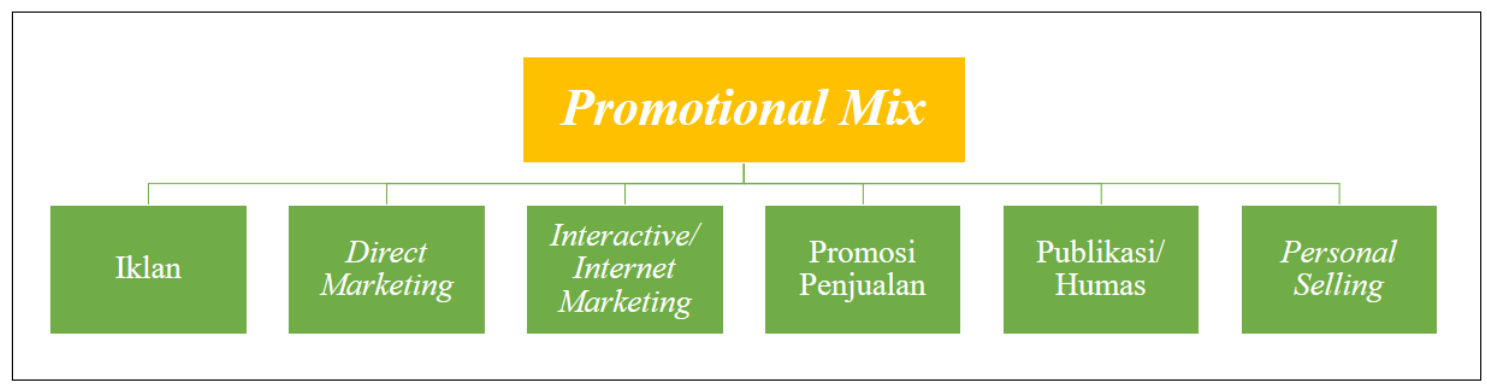

Gambar 1. Promotional Mix (Morissan, 2013)

Gambar di atas menjelaskan tentang pendapat Belch \& Belch yang merumuskan bauran promosi kedalam beberapa elemen yaitu iklan, promosi penjualan, public relation, personal selling, direct marketing, dan interactive/internet marketing. Dari enam elemen ini, iklan dan public relation dipandang sebagai metode promosi utama media penyiaran radio. Bukan hanya itu, promosi melalui media sendiri termasuk salah satu metode promosi utama karena kecepatan dan kemudahannya (Morrisan, 2013).

Menurut Djamal \& Fachruddin (2013) marketing ghatering merupakan metode yang dapat dilakukan dalam rangka promosi program media penyiaran radio. Marketing gathering merupakan sebutan lain dari seminar atau presentasi yang dilakukan dalam kegiatan pemasaran yang menghadirkan para calon pemasang iklan. Berbagai hal yang berkaitan dengan program siaran dikemukakan dalam presentasi ini.

Artikel ini ditulis untuk melengkapi kajian tentang promosi dan program dakwah radio. Temuan penelitian Surianor (2016) mengungkapkan bahwa 16 radio siaran swasta di Provinsi Kalimantan Selatan menyiarkan program dakwah dengan presentasi sangat kecil, sebab pemilik radio sebagian besar dari kalangan Tionghoa non muslim. Temuan penelitian Setiawan \& Latifa (2019) menunjukkan bahwa public relations Radio Geronimo Yogyakarta menjalankan fungsi mempertahankan citra dengan menggarap segmentasi pasar khusus yaitu kelompok anak muda. Pembahasan tentang public relations sangat berhubungan dengan promosi sebab public relations merupakan salah satu elemen dalam bauran promosi. Artikel ini ditulis dengan tujuan mendeskripsikan promosi program dakwah Radio Selebes Gorontalo. Jawaban atas dua pertanyaan berikut menjadi inti pembahasan artikel ini. Pertama, apa saja program dakwah Selebes? Kedua, apa dan bagaimana metode promosi program dakwah Selebes?

\section{METODE PENELITIAN}

Metodologi kualitatif dengan model studi kasus digunakan untuk memahami fenomena promosi program dakwah Radio Selebes. Creswell mengemukakan bahwa salah satu alasan yang mendasari penggunaan metodologi kualitatif adalah pertanyaan penelitian yang dimulai dengan kata "how" dan "what" yang menandakan bahwa peneliti menginginkan informasi mendalam tentang fenomena yang ditelitinya (Herdiansyah, 2014). Menurut Stake, studi kasus merupakan strategi penelitian untuk menyelidiki secara cermat sebuah program, peristiwa, aktifitas, proses, atau sekelompok individu (Creswell, 2010). Menurut Bungin (2015) proses-proses yang memerlukan penjelasan dan pemahaman yang lebih luas bisa diketahui dengan menggunakan model penelitian ini.

Subjek penelitian ini adalah Radio Selebes. Radio yang berdiri sejak 4 Mei 1989 ini menyiarkan 20 program dengan lebih dari 200 lagu dalam satu hari. Selebes merupakan radio swasta tertua di Gorontalo dengan tagline The 
Best Biggest and Oldest Radio Station in Gorontalo (Selebesgroup.com, n.d.). Walaupun bukan radio dengan format khusus agama Islam, Selebes tetap menyiarkan program dakwah untuk memenuhi kebutuhan pendengarnya akan kontenkonten dakwah.

Informan dalam penelitian ini adalah manajemen dan karyawan Selebes yang mampu memberikan informasi secara mendalam mengenai Selebes terutama tentang promosi program dakwahnya. Wawancara tidak terstruktur digunakan demi mendapatkan jawaban yang lebih luas dan bervariasi mengenai promosi program dakwah.

Pedoman wawancara yang hanya berisi tema inti saja digunakan untuk mengontrol jalannya wawancara. Pertanyaan-pertanyaan yang diajukan adalah pertanyaan terbuka, yang didominasi oleh pertanyaan mengarahkanterbuka. Studi dokumentasi juga dilakukan untuk memperoleh data dari sejumlah dokumen internal seperti jadwal siaran, deskripsi program dan rundown siaran, naskah dan rekaman adlibs, naskah dan rekaman iklan, rekaman siaran, flyer promosi, serta berbagai informasi terkait yang ditampilkan melalui website dan akun media sosial Selebes.
Data yang telah dikumpulkan, dianalisis dengan cara manual tanpa software analisis data. Kemudian, data diurai agar dapat dipahami. Proses analisis ini berlangsung sejak awal sampai akhir penelitian. Selanjutnya, data digabungkan dan diseragamkan dalam bentuk tulisan yang bisa dianalisis, kemudian ditampilkan berdasarkan tema-tema yang muncul. Pada tahap terakhir, kesimpulan yang diberikan menjadi jawaban atas pertanyaan penelitian yang diajukan.

\section{HASIL DAN PEMBAHASAN}

\section{Program Dakwah}

Kontribusi Selebes dalam pengembangan dakwah di Gorontalo tercermin melalui keberadaan program dakwah dalam siarannya. Hal ini sejalan dengan pendapat Nasor (2017) tentang kontribusi dan pengaruh radio dalam perkembangan dakwah. Menurutnya, radio memiliki andil, fungsi, dan peran dalam kegiatan dakwah. Menurut Munir, radio merupakan salah satu media yang dapat digunakan dalam kegiatan dakwah. Siaran keagamaan atau program dakwah yang disajikan oleh hampir semua radio di Indonesia mengindikasikan bahwa radio sedang menjalankan fungsi edukasi yang dimilikinya (Rosidi \& Zain, 2019).

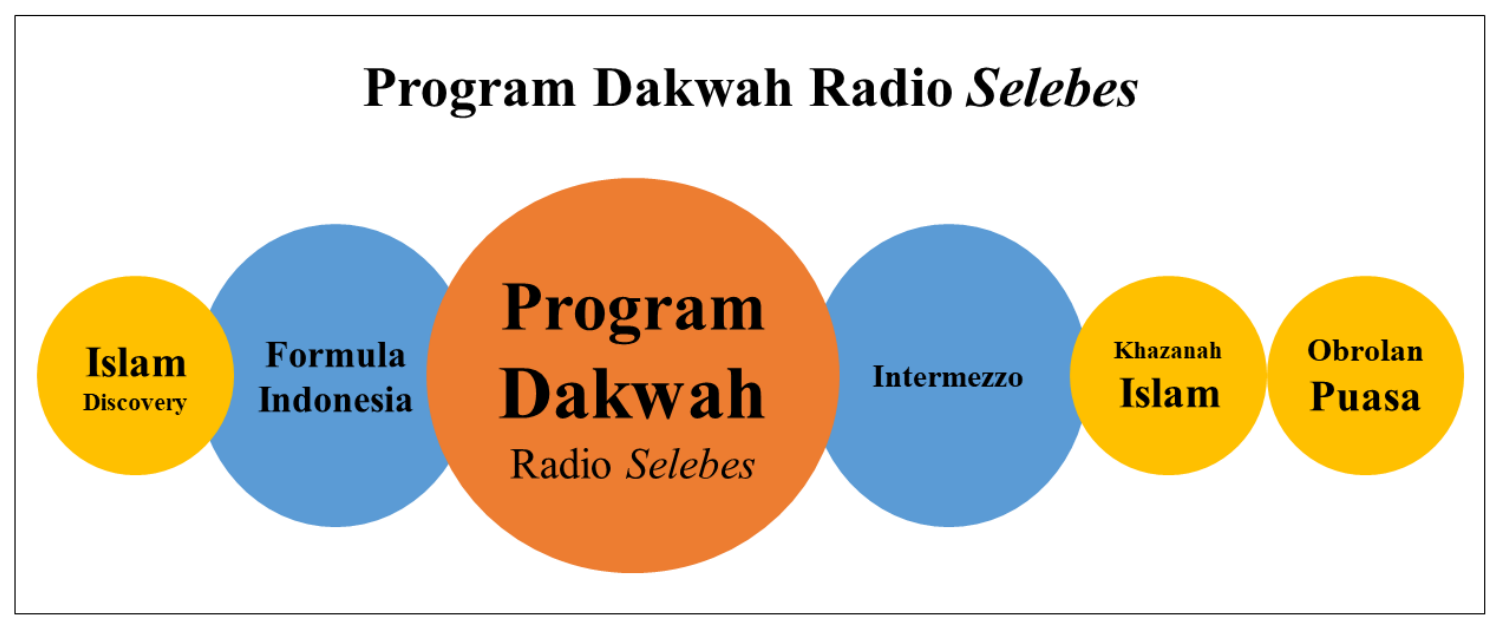

Gambar 2. Program Dakwah Radio Selebes (Olahan Peneliti, 2020)

Gambar di atas menunjukkan bahwa Selebes menyiarkan tiga program dakwah yaitu: (1) Islam Discovery; (2) Khazanah Islam; dan (3)
Opus. Islam Discovery merupakan bagian dari program Formula Indonesia yang mengudara setiap hari Senin sampai Jumat, mulai jam 9 pagi 
sampai jam 12 siang. Pada hari Senin Formula Indonesia mengusung tema Karir dan Pekerjaan yang sekaligus menjadi nama kedua bagi program ini, pada hari Selasa Dunia Kesehatan, pada hari Rabu Trend dan Perilaku, pada hari Kamis Ruang Perempuan. Sementara pada hari Jumat diberi nama Islam Discovery. Berbeda dengan program pada hari Senin sampai Kamis, Formula Indonesia Islam Discovery hanya memutarkan lagu-lagu islami dan menghadirkan informasi-informasi yang berhubungan dengan dunia Islam. Selain itu, pada program ini, pendengar disuguhkan dengan lantunan ayat-ayat Al-Quran pilihan pada jam 11 lebih 30 menit sampai jam 12 siang.

Program dakwah berikutnya adalah Khazanah Islam. Program ini merupakan bagian dari program Intermezzo yang mengudara setiap hari pada jam 5 sampai jam 6 sore. Khazanah Islam dimulai pada jam 5 lebih 30 menit ditandai dengan diputarnya lagu-lagu bernuansa Islam. Sebelum azan Maghrib diputar tepat pada waktunya, pada program ini pendengar disuguhkan dengan lantunan ayat-ayat Al-Quran dan ceramah agama yang diproduksi oleh Mitradio yang menjadi partner Selebes dalam menyediakan konten-konten audio islami.

Program dakwah terakhir adalah Opus yang merupakan singkatan dari Obrolan Puasa. Program dakwah ini hanya mengudara pada bulan Ramadan. Sama halnya dengan Khazanah Islam, Opus pun merupakan bagian dari program Intermezzo. Yang membedakan keduanya adalah, jika Khazanah Islam menghadirkan ceramah agama menjelang waktu Maghrib, maka Opus hadir dengan obrolan antara narasumber dengan penyiar sampai waktu buka puasa tiba.
Narasumber yang hadir dalam program ini adalah mereka yang diutus oleh lembaga atau organisasi Islam yang bekerja sama dengan Selebes. Bukan hanya itu, sebagai program interaktif, pendengar dapat menyampaikan pertanyaan melalui saluran telepon, SMS, WhatsApp atau pesan Instagram untuk dibahas oleh narasumber dalam program ini.

\section{Promosi Program Dakwah}

Temuan penelitian ini menunjukkan bahwa promosi program dakwah tetap dilakukan meskipun manajemen Selebes mengklaim bahwa program dakwah tetap didengar walau minim promosi, bahkan tanpa promosi. Selain karena penduduk Gorontalo mayoritas beragama Islam, anggapan akan hal ini diperkuat lagi dengan keberhasilan Selebes bertahan dalam persaingan industri media penyiaran radio di Gorontalo sejak tahun 1989 sampai dengan sekarang. Walaupun belum dilakukan secara maksimal, bagi Selebes tujuan dipromosikannya program dakwah adalah memperkenalkan program itu, menambah jumlah pendengar dan pemasang iklan.

Temuan ini relevan dengan pendapat Morrisan (2013) bahwa promosi program dilakukan untuk mempertahankan dan menambah pendengar serta mengundang pemasang iklan. Program dakwah Radio Selebes dipromosikan menggunakan empat metode yaitu: (1) media sendiri; (2) iklan; (3) promosi penjualan; dan (4) pemasaran interaktif.

Morrisan (2013) berpendapat bahwa program media penyiaran dapat dipromosikan melalui berbagai metode yaitu promosi melalui media sendiri, $P R$, iklan, atau kombinasi dari tiga metode ini. 


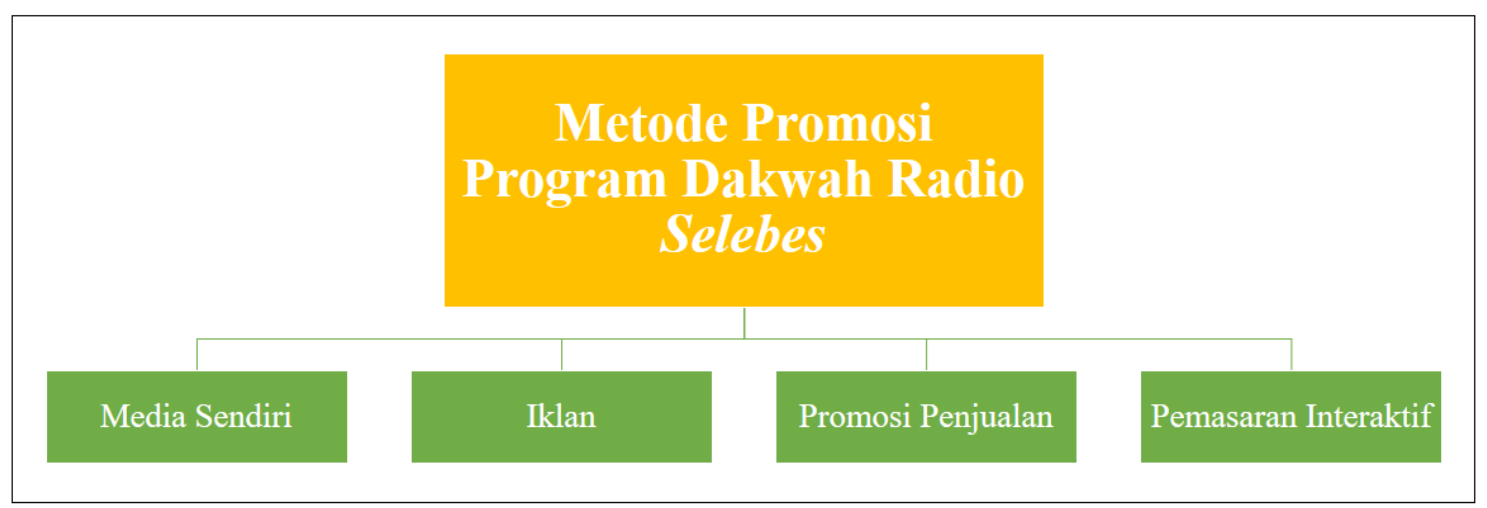

Gambar 3. Metode Promosi Program Dakwah Radio Selebes (Olahan Peneliti, 2020)

\section{Media Sendiri dan Promosi Penjualan}

Mempromosikan program dakwah melalui media sendiri telah dilakukan sejak lama oleh Selebes. Promosi menggunakan metode ini diharapkan bisa mempertahankan dan meningkatkan jumlah pendengar serta pemasang iklan. Bagi Selebes, metode ini merupakan metode sederhana, mudah dan murah. Promosi program dakwah melalui media sendiri dilakukan dengan menggunakan jingle program radio dan adlibs (iklan yang dibacakan langsung oleh penyiar).

Bukan itu saja, promosi program dakwah melalui media sendiri ternyata porsinya lebih besar dibandingkan dengan program non dakwah. Temuan ini relevan dengan pendapat Morrisan (2013) bahwa tempat terbaik mempromosikan program adalah di media sendiri. Metode ini merupakan metode paling cepat dan mudah dilakukan. Promosi program menggunakan metode ini bertujuan untuk memberi tahu pendengar agar mereka mengikuti program yang akan disiarkan. Selain itu, metode ini dipandang sebagai seni mempertahankan pendengar agar tidak pindah ke media penyiaran lain. Sehingga, penting bagi media penyiaran termasuk radio untuk memaksimalkan penggunaan metode ini demi mencapai tujuannya.

Metode promosi penjualan hanya digunakan untuk program Opus. Bentuk promosi penjualan yang diterapkan dalam promosi Opus adalah kuis berhadiah. Hadiah diberikan kepada pendengar yang menjawab benar pertanyaan dalam program Opus. Hadiah yang diberikan diantaranya berupa voucher pulsa, voucher makan dan voucher diskon yang disediakan oleh para pengiklan pada jam siaran Opus. Selain memberikan manfaat bagi Selebes berupa peningkatan jumlah pendengar program dakwah, kuis berhadiah ini mampu meningkatan jumlah konsumen para pemasang iklan pada jam siaran Opus.

Sejalan dengan temuan ini, Morrisan (2013) mengemukakan bahwa promosi penjulan atau sales promotion merupakan instrumen yang dapat digunakan oleh media penyiaran untuk menarik minat pendengar terhadap program siaran. Kuis berhadiah sebagai bentuk kegiatan promosi penjualan yang dilakukan oleh Selebes selama ini merupakan wujud dari costumeroriented sales promotion atau promosi penjualan berorientasi konsumen yang mencakup pemberian kupon, pemberian sampel produk, potongan harga, undian berhadiah dan kontes. Meskipun pendengar tidak loyal, hadiah yang ditawarkan diharapkan dapat merangsang minat pendengar terhadap media penyiaran dan programnya.

\section{Iklan}

Iklan (advertising) merupakan bagian dari elemen bauran promosi yang terus mengalami pertumbuhan. Hasil temuan Nielsen Advertising Intelligence menyebutkan bahwa dibandingkan dengan tahun 2018, belanja iklan pada tahun 
2019 mengalami pertumbuhan sebesar 10 persen. Total belanja iklan pada tahun 2019 mencapai 168 triliun rupiah. Jumlah ini sudah termasuk total belanja iklan radio yang mencapai 1,7 triliun rupiah (Nielsen.com, 2020). Mempromosikan program radio melalui iklan sama halnya dengan membeli dari media yang lain. Terdapat beberapa kasus media penyiaran tidak mengeluarkan rupiah untuk membayar iklan mereka di media penyiaran lain. Yang dilakukan oleh dua media penyiaran seperti ini adalah barter atau tukarmenukar iklan (Morissan, 2013).

Temuan penelitian ini menunjukkan bahwa selain menyiarkan iklan program dakwah dalam bentuk jingle dan adlibs di media sendiri, iklan program dakwah Selebes disiarkan pula di Radio SKFM. Tidak semua program dakwah Selebes diiklankan di sana. SKFM hanya menyiarkan iklan Opus saja, sebab radio ini me-relay program yang sama. Selebes juga mengiklankan program Opus di Koran GorontaloPost. Iklan program dakwah Selebes di SKFM dan GorontaloPost adalah iklan gratis. Selebes tidak mengeluarkan biaya pemasangan iklan program dakwah sebab SKFM merupakan radio yang dikelola dalam satu group yang sama dengan Selebes. Sementara GorontaloPost, ada kesepakatan barter iklan antara dua media ini. Memasang iklan di media lain seperti televisi dan media alternative tidak dilakukan oleh Selebes dalam promosi program dakwahnya sebab pertimbangan biaya yang akan timbul. Selama ini penggunaan iklan melalui media alternative lebih difokuskan untuk promo brand Selebes, seperti sticker yang dipasang pada kaca mobil kendaraan pribadi dan kendaraan umum.

Menurut Morissan (2013), media cetak seperti surat kabar dan majalah sering digunakan oleh media penyiaran televisi dan radio untuk mengiklankan media penyiaran atau program siaran mereka. Bukan hanya itu, billboard atau papan reklame luar ruang juga kerap menjadi pilihan bagi media penyiaran utamanya radio untuk beriklan, sebab pesan yang ditampilkan dalam billboard diyakini mampu menggerakkan orang untuk segera mencari saluran radio yang diiklankan. Iklan media penyiaran biasanya hadir pula dalam bentuk poster di terminal bus, stasiun kereta, pelabuhan dan bandara. Bahkan iklan media penyiaran dapat ditemukan di dalam kendaraan seperti bus dan kereta. Soemanagara (2012) menyebutnya dengan transit advertising yang terdiri dari beberapa bentuk diantaranya out side poster, inside cards, station platform, dan terminal poster. Temuan penelitian ini menunjukkan, program siaran dakwah tidak dipromosikan menggunkan billboard dan transit advertising.

\section{Pemasaran Interaktif}

Hasil riset yang dilakukan oleh HootSuite dan We Are Social (Hotsuite, 2020) menunjukkan bahwa pengguna internet di Indonesia telah mencapai 175,4 juta orang pada tahun 2020 . Sementara, pengguna aktif media sosial sebanyak 160 juta orang (Inet.detik.com, 2020). Kondisi ini tentu saja menjadi "alarm" bagi berbagai perusahaan termasuk media penyiaran untuk menaruh perhatian lebih terhadap pemasaran interaktif atau internet marketing sebagai sebuah metode promosi. Morrisan (2013) berpendapat bahwa internet dapat digunakan untuk melaksanakan seluruh elemen bauran promosi. Internet dapat digunakan untuk beriklan, promosi penjualan, penjualan personal, pemasaran langsung dan public relation. Semua elemen bauran pemasaran dapat dilakukan lebih efektif dan efisien dengan internet.

Internet dimanfaatkan oleh Selebes sebagai media promosi sejak tahun 2015. Media sosial digunakan lebih awal dibandingkan website. Akun Facebook dan Twitter Selebes digunakan terakhir kali sebagai sarana promosi pada tahun 2017. Dua platform ini tidak lagi digunakan karena keterbatasan sumber daya manusia yang mengelolanya. Hingga saat ini, promosi melalui metode pemasaran interaktif hanya dilakukan melalui akun Instagram, WhatsApp dan website 
Selebes saja. Program dakwah dipromosikan pula melalui WhatsApp status, Instagram dan akun Facebook pribadi manajemen dan karyawan Selebes. Bukan hanya itu, akun media sosial milik pengisi acara dan lembaga yang terlibat dalam program dakwah pun dimanfaatkan untuk promosi program ini. Hal ini tentu saja dilakukan dalam rangka memaksimalkan promosi program dakwah.

\section{Public Relation}

Public Relation (PR) didefiniskan oleh Cutlip et al. (2011) sebagai fungsi manajemen yang membangun dan mempertahankan hubungan baik dan bermanfaat antara organisasi dengan publiknya. Fungsi manajeman ini berpengaruh pada kesuksesan atau kegagalan organisasi. Sementara itu, Edward L. Bernays mengemukakan bahwa $P R$ mempunyai tiga arti yaitu penerangan kepada publik, perusasi kepada publik untuk mengubah sikap dan tingkah laku mereka, serta upaya untuk menyatukan sikap dan perilaku suatu lembaga (Ardianto, 2016).

$P R$ merupakan sarana promosi massal yang dilakukan dengan menjalin hubungan dengan berbagai konsumen perusahaan dan masyarakat umum. Tujuannya adalah membangun citra perusahaan yang positif agar memperoleh publisitas yang luas, mengatasi kabar angin atau laporan atau kejadian yang tidak sesuai kenyataan. Masyarakat yang dimaksud adalah kelompok yang memiliki hubungan dengan perusahaan termasuk konsumen, kompetitor, pemerintah, dan organisasi sebagai konsumen. Support perusahaan terhadap proyekproyek kemanusiaan, keikutsertaan perusahaan dalam kegiatan sosial, perusahaan menjadi sponsor pada berbagai kegiatan olahraga dan seni, dan beragam aktifitas lainnya diyakini dapat memberikan kontribusi terhadap keberhasilan $P R$ perusahaan mencapai tujuannya (Machfoedz, 2010).

Menurut Morrisan (2013) membentuk persepsi masyarakat atas media penyiaran merupakan tujuan kegiatan $P R$ dalam pengelolaan media penyiaran radio. Promosi dapat dilakukan secara langsung kepada masyarakat atau off-air promotion melalui berbagai kegiatan seperti jumpa pers, menghadirkan selebriti atau orang terkenal, menonton program dan pelayanan masyarakat.

Jika Morrisan (2013) berpendapat bahwa $P R$ merupakan salah satu metode utama dalam promosi program media penyiaran, temuan penelitian ini justru menunjukkan hal sebaliknya. Bagi Selebes, $P R$ bukan metode utama dan tidak diaplikasikan sama sekali dalam promosi program dakwah. Walaupun bukan metode promosi program dakwah, $P R$ ternyata digunakan untuk mempromosikan brand Selebes secara umum. Banyak kegiatan $P R$ yang telah dilakukan, diantaranya kegiatan pelatihan broadcasting, kegiatan donor darah, dan kunjungan ke panti asuhan.

\section{KESIMPULAN}

Kontribusi Selebes dalam pengembangan dakwah tampak pada kehadiran program dakwah dalam siaran mereka. Tiga program dakwah Selebes dipromosikan menggunakan empat metode yaitu: (1) media sendiri; (2) iklan; (3) promosi penjualan; dan (4) pemasaran interaktif. Metode promosi ini diterapkan dengan tujuan mempertahankan dan meningkatkan jumlah pendengar serta pemasang iklan, agar Selebes dapat terus melanjutkan operasionalnya. Kekhawatiran akan dampak biaya akibat kegiatan promosi menjadi penyebab terbatasnya variasi metode yang digunakan. Selama ini, Selebes menggunakan metode yang mudah dan murah. Public relation digunakan sebagai metode promosi, namun tidak digunakan secara khusus untuk promosi program dakwah seperti empat metode lainnya.

\section{ACKNOWLEDGMENT}

Terima kasih kepada Yowan Tamu, M.A, dosen Fakultas Ilmu Sosial, Universitas Negeri 
Gorontalo, dan Sunandar Macpal, M.A, dosen Fakultas Ushuluddin dan Dakwah, Institut Agama Islam Negeri Sultan Amai Gorontalo yang telah membaca draft awal artikel ini. Seluruh isi artikel ini menjadi tanggung jawab penulis.

\section{REFERENCES}

Ardianto, E. (2016). Handbook of Public Relations: Pengantar Komprehensif. Bandung: Simbiosa Rekatama Media.

Bps.go.id. (2019). Persentase Penduduk

Berumur 5 Tahun ke Atas yang Mendengarkan Siaran Radio Selama Seminggu Terakhir menurut Provinsi, Tipe Daerah dan Jenis Kelamin, 2018.

Bungin, B. (2015). Analisis Data Penelitian

Kualitatif: Pemahaman Filosofis dan

Metodologis ke Arah Penguasaan

Model Aplikasi. Jakarta: Rajawali Pers.

Creswell, J. (2010). Research Design:

Pendekatan Kualitatif, Kuantitatif, dan Mixed. Yogyakarta: Pustaka Pelajar.

Cutlip, S., Center, A., \& Broom, G. (2011). Effective Public Relations (9th ed.). Jakarta: Kencana.

Djamal, H., \& Fachruddin, A. (2013). DasarDasar Penyiaran: Sejarah, Organisasi, Operasional, dan Regulasi. Jakarta: Kencana.

Gorontalo.bps.go.id. (2018). Persentase Penduduk Menurut Kabupaten/Kota dan Agama di Provinsi Gorontalo, 2017.

Herdiansyah, H. (2014). Metodologi Penelitian Kualitatif untuk Ilmu-ilmu Sosial. Jakarta: Salemba Humanika.

Hotsuite. (2020). Digital 2020 Report. Retrieved from We Are Social website: https://wearesocial.com/blog/2020/01/di gital-2020-3-8-billion-people-use- social-media

Inet.detik.com. (2020). Riset: Ada 175,2 Juta Pengguna Internet di Indonesia.

Machfoedz, M. (2010). Komunikasi Pemasaran Modern: Acuan Wajib Mahasiswa \& Profesional. Yogyakarta: Cakra Ilmu.

Morissan. (2013). Manajemen Media Penyiaran: Strategi Mengelola Radio \& Televisi. Jakarta: Kencana.

Nasor, M. (2017). Optimalisasi Fungsi Radio Sebagai Media Dakwah. Al-Adyan: Jurnal Studi Lintas Agama, 12(1), 105128.

Nielsen.com. (2016). Radio Masih Memiliki Tempat di Hati Pendengarnya.

Nielsen.com. (2020). Belanja Iklan 2019 Ditutup dengan Tren Positif.

Prisgunanto, I. (2006). Komunikasi Pemasaran: Strategi \& Taktik. Bogor: Ghalia Indonesia.

Rahayu, T. Y., \& Katili, K. R. D. (2019). Strategi Program Radio dalam Mempertahankan Eksistensinya. MAKNA : Jurnal Kajian Komunikasi, Bahasa Dan Budaya, 4(1), 139-153. https://doi.org/https://doi.org/10.33558/ makna.v4i1.1677

Rosidi, I., \& Zain, R. (2019). Strategi Radio Republik Indonesia (RRI) Pekanbaru dalam Menyampaikan Program Siaran Dakwah. Idarotuna, 1(2).

Rusdi, F. (2011). Strategi Komunikasi Pemasaran Program Interaktif di Media Radio. Jurnal ASPIKOM, 1(3), 245. https://doi.org/10.24329/aspikom.v1i3.2 3

Selebesgroup.com. (n.d.). About Us. 
Setiawan, B., \& Latifa, A. (2019). Strategi Public Relations Radio Geronimo Yogyakarta dalam Mempertahankan Citra Perusahaan. Mediator: Jurnal Komunikasi, 12(2), 189-198.

https://doi.org/10.29313/mediator.v12i2. 4897

Soemanagara, R. (2012). Strategic Marketing Communication: Konsep Strategis dan Terapan. Bandung: Alfabeta.

Surianor. (2016). Analisis Program Dakwah pada Radio-Radio Siaran Swasta Niaga di Kalimantan Selatan. Jurnal Ilmu Dakwah, 15(29), 15-33.

Tafsirweb.com. (n.d.). Quran Surat An-Nahl Ayat 125 .

Tirto.id. (2019). Cara Radio Bertahan: Merambah ke Media Online hingga Jualan Obat.

Zain, A., Maimun, \& Fuadi, M. (2017). Identifikasi Ayat-Ayat Dakwah dalam Al-Qur'an. Al-Idarah: Jurnal Manajemen Dan Administrasi Islam, 1(2), 167-188. 